\title{
PERAN IBU DALAM BERKARIR DAN KEHIDUPAN BERKELUARGA
}

\author{
Dian Bagus Mitreka Satata \\ Psikologi, Universitas Muhammadiyah Malang \\ dbagus@webmail.umm.ac.id \\ Methania Aris Shusantie \\ Universitas Negeri Malang \\ methaniaaris@gmail.com
}

\begin{abstract}
Abstrak
Tujuan penelitian ini adalah untuk mengetahui kesanggupan dalam menyeimbangkan peran ganda seorang ibu sebagai wanita karir yang sudah berkeluarga. Saat ini seorang ibu tidak hanya mampu menjadi seorang ibu rumah tangga namun mampu berekspresi untuk mengaktualisasikan diri menjadi apa yang diinginkan sesuai kebutuhan dirinya. Terdapat berbagai faktor wanita yang sudah berkeluarga untuk tetap berkarir salah satunya yaitu untuk meningkatkan kesejahteraan psikologis. Subjek penelitian terdapat empat partisipan wanita bekerja yang sudah berkeluarga. Data primer didapatkan dengan wawancara mendalam, data sekunder didapat melalui observasi serta catatan lapangan. Metode yang digunakan adalah pendekatan kualitatif studi kasus fenomenlogi. Hasil mengungkapkan bahwa ibu sebagai wanita karir mampu mengatur keseimbangan (work-life balance) sehingga dapat menyelaraskan antara karir dan berkeluarga.
\end{abstract}

Kata kunci: Ibu rumah tangga, wanita karir, keluarga, work-balance

\begin{abstract}
The purpose of this research is to find out the ability to balance a mother's dual role as a career woman who is already in a family. Nowadays a mother is not only able to be a housewife but able to express herself to realize herself into what she wants to be. There are various factors of women who have families to keep a career, one of which is to improve psychological well-being. The study subjects included four working female participants who were already in a family. Primary data is obtained by in-depth interviews, secondary data obtained through observations as well as field records. The method used is a qualitative approach to phenomenological case studies. Results reveal that mothers as career women are able to manage work life balance so that they can align between career and family.
\end{abstract}

Keywords: house wife, career women, family, work-life balance 


\section{PENDAHULUAN}

Bekerja merupakan hak setiap individu dalam mengaktualisasikan diri mereka pada pemenuhan tertentu. Dengan bekerja seseorang dapat memberikan efek positif pada diri sendiri maupun pada organisasi kerja. Efek secara langsung yaitu dapat bersosialisasi dengan individu sehingga mampu meningkatkan kesejahteraan psikologis (Putri, 2019). Hal ini lumrah bila dilakukan oleh seorang laki-laki yang berkewajiban sebagai pencari nafkah dalam kehidupan keluarga, namun fenomena yang terjadi sangat banyak wanita atau ibu yang bekerja untuk pemenuhan dari dorongan tertentu (Braun \& Turner, 2014).

Ibu memiliki peran sebagai menjaga dan mendidik anak agar menjadi generasi yang lebih cerdas, namun peran ibu sebagai wanita karir dan ibu rumah tangga tidaklah mudah dilakukan perlu profesionalitas tinggi dalm menjalankan keduanya (Mayangsari \& Amalia, 2018). Banyak konflik yang terjadi pada beberapa rumah tangga yang memiliki figur ibu berperan ganda sebagai wanita karir (Ermawati, 2016). Maka hal ini menjadi sebuah fenomena menarik bagaimana seorang ibu mampu menjalankan dan menyeimbangkan peran ganda sebagai ibu karir dan ibu rumah tangga (Dhas \& Karthikeyan, 2015).

Wanita karir merupakan wanita yang melakukan pekerjaan sesuai dengan bidang ilmu dan keahliannya, secara umum wanita karir merupakan wanita yang memiliki pendidikan tinggi dan mempunyai status yang cukup tinggi dalam pekerjaanya dan berkarya (Ermawati, 2016; Liu et al, 2020). Ditemukan juga bahwa terdapat dampak yang mungkin berpengaruh pada hubungan sosial sehingga terjadi kecemburuan sosial yang dapat menimbulkan obsesi pada karir (Abalkhail, 2020). Selain itu diskriminasi gender menjadi salah satu faktor menyebab ibu enggan untuk berkarir atau kurangnya keseimbangan mengatur keluarga dan bekerja (Al-Asfour et al, 20107).

Peran ganda pada seorang wanita yang sudah berkelurga memberi tuntutan dan permasalahan yang tinggi, namun tergantung pada individunya ada yang merasa menikmati dan ada yang merasa keberatan dengan harus berkarir dan berutmah tangga. Seorang wanita yang memilih untuk memproritaskan karir maka akan mengorbankan waktu bersama keluarga, namun bila memilih keluarga akan menurunkan kinerja (Paramitha, 2004). Akan terdapat konflik yang dinamakan workfamily conflict karena tidak dapat menjalankan peran yang terbagi antara karir dan tanggung jawab sebagai ibu rumah tangga (Frone et al, 1992).

Namun faktanya banyak ibu yang mampu menyeimbangkan karirnya di dunia militer dengan kehidupan keluarga (Masita et al, 2019), bahkan pada bidang perhotelan wanita mampu mengembangkan bakat dan kemampuannya sehingga mampu memiliki jabatan tinggi (Liu et al, 2020). Selain itu temuan lain mengatakan bahwa wanita karir mampu mengembangkan dan mempelajari kemampuan serta menambah pengalaman yang baru bagi diri mereka (Clarke, 2011). Keselarasan peran atau work-life balance diharapkan ada pada wanita karir yang berkeluarga sehingga mampu memainkan peran yang seimbang agar terbebas dari masalah kesehatan mental seperti stress, depresi, cemas, dan sebagainya (Kaur, 2013).

Pada umumnya laki-laki dan perempuan memiliki beban dan tanggung jawab yang proporsional (Shockley et al, 2017), namun hal ini tergantung pada kebutuhan individu untuk mengekspresikan dirinya melalui aktualisasi diri manusia (Rogers, 1975). Kemudian terhadap konsep diri yang kuat bahwa wanita juga dapat berkarir dan mandiri sehingga mampu mengevaluasi diri sendiri (Ahmad \& Tekke, 2015). Tidak 
sedikit seorang ibu memilih berkarir agar dapat mandiri dan dapat membantu ekonomi keluarga.

Namun perlu dipahami peran ganda dapat menimbulkan konflik dan dilema yang beragam dari berbagai individu dengan kapasitas secara fisik, psikologis, dan lingkungan eksternal (Halida 2013; Murtiana \& Hidayah, 2017). Maka tujuan penulisan penelitian ini adalah untuk mengetahui dalam menyeimbangkan peran ganda seorang ibu sebagai wanita karir dan ibu rumah tangga. Diharapkan hasil penelitian ini dapat menjadi rujukan pada hubungaan sosial keluarga dan ilmuwan pada bidang psikologi dan sosial maupun praktisi.

\section{METODE}

Metode yang digunakan dalam penelitian ini adalah pendekatan kualitatif studi kasus fenomenlogi dengan tujuan untuk menganilisa dan mengungkap keseimbangan peran ganda dari dari ibu sebagai wanita karir dan ibu rumah tangga. Penelitian kualitatif dalam psikologi merupakan metode penelitian yang mendeskripsikan objek penelitian melalui prosedur dan data yang bersifat non numerikal terhadap objek psikologi seperti data verbal, teknik analisis isi, kelompok fokus, dan fenomenologi untuk mengungkap objek fenomena psikologi (Hanurawan, 2012).

Penelitian ini mengambil data dari empat orang partisipan wanita karir yang bekerja di perusahaan swasta dan pegawai negeri sipil (PNS) yang sudah berkeluarga. Metode pengumpulan data yang digunakan adalah wawancara dan observasi, teknik wawancara yang digunakan adalah wawancara tidak terstruktur. Wawancara tidak terstruktur yaitu digunakan untuk menemukan informasi yang bukan buku atau informasi tunggal, sehingga lebih bebas iramanya dan responden biasanya dipilih karena sifat- sifatnya yang khas (Basrowi \& Suwandi, 2008).

Sebelumnya peneliti melakukan observasi langsung terhadap partisipan dalam kegiatan sehari-hari selama beberapa hari, dalam pelaksanaan proses wawancara, pewawancara dan partisipan melakukan diskusi mengenai sebuah topik yang relevan dengan tujuan penelitian kemudian diikuti dengan pertanyaan yang berkaitan terhadap peran ganda seorang ibu dalam berkarir dan ibu rumah tangga. Analisis data dilakukan pada saat wawancara dan observasi berlangsung secara interaktif dan berlangsung secara kontinyu hingga tuntas. Kemudian dilakukan tahap (1) reduksi data agar data tidak kompleks dan rumit, (2) penyajian data agar informasi dapat terorganisir dengan baik, (3) langkah berikutnya penarikan kesimpulan (Sugiyono, 2011). Keabsahan data dilakukan dengan membandingkan data penelitian yang diperoleh dengan beberapa sumber data yang lain.

\section{HASIL DAN PEMBAHASAN}

Berdasarkan hasil penelitian diketahui bahwa keemapt partisipan penelitian mengungkapkan bahwa berkarir dan berkeluarga merupakan kebutuhan yang seimbang, hal ini sejalan dengan hasil observasi sebelumnya. Tiga dari empat partisipan merasa lebih sehat secara psikis ketika berkarir dan berkativitas di luar rumah, selain itu partisipan menganggap dapat membantu pengeluaran kebutuhan seharihari. Hal ini sejalan dengan penelitian sebelumnya bahwa wanita mampu berkarir dengan baik mengaktualisasikan dirinya untuk lebih berkembang (Utami, 2011). Empat partisipan merupakan seorang ibu yang sudah berkeluarga masih memiliki pasangan dan dikaruniai anak, usia sekitar 30-40 tahun dengan masa kerja lebih dari 5 tahun pada masing-masing sektor. 
Dua partisipan bekerja PNS pada insititusi pemerintahan di salah satu kota di Provinsi Jawa Timur sehingga menyatakan bahwa dirinya lebih sejahtera daripada hanya menjadi ibu rumah tangga, disamping itu partisipan menyatakan bahwa dia mampu berbisnis sembari bekerja. Dua partisipan lain bekerja pada perusahaan swasta bidang informasi \& teknologi (IT) di Jawa Timur dengan pengalaman yang cukup lumayan sehingga mampu mengembangkan minat, namun satu partisipan menyatakan bahwa terdapat kesenjangan sosial dari segi job desc sehingga menimbulkan konflik secara mental namun tidak signifikan karena ada faktor lain yang menjadi pendukung.

Secara garis besar tidak terdapat masalah dengan work-life balance pada wanita berperan ganda, seperti yang diungkapkan pada hasil penelitian sebelumnya bahwa bekerja tidak menghambat waktu bersama keluarga (Ermawati, 2016; Masita et al, 2019). Konflik dalam kehidupan bekerja tidak begitu terasa karena wanita mampu mengekspresikan diri melalui lingkungan sosial dalam organisasinya, selain itu latar belakang pendidikan para partisipan yang tergolong tinggi. Pendidikan menjadi motivasi dalam berkarir karena merasa dirinya lebih mampu untuk berkontribusi di dunia kerja (Dewi et al, 2016).

Partisipan memiliki motivasi yang sama yaitu untuk membantu perekonomian keluarga dan bisa lebih mandiri. Hal ini disebutkan oleh salah satu partisipan bahwa dirinya merasa menikmati apa yang menjadi impian dari sejak dini, selain itu partisipan lain beranggapan bahwa ketika tua nanti mereka membutuhkan lingkup sosial atau "circle" agar dapat terhindar masalah kesehatan penuanaan seperti alzaimer, stress, dan cemas karena kesepian. Hal ini sejalan dengan haisl temuan penelitian sebelumnya bahwa dengaan bekerja wanita dapat mencegah terjadinya masalah kesehatan mental dan psikologis (Kaur, 2013).

Dari hasil wawancara telah disebutkan bahwa partisipan lebih memilih untuk berkarir meski sudah berumah tangga, hasil sebelumnya juga diungkapkan bahwa bekerja dapat menurunkan tingkat stres daripada hanya beraktivitas di dalam rumah. Dari hasil observasi wanita yang berperan ganda juga mampu melakukan bisnis dengan berjualan secara online maupun langsung "door to door" kepada rekan kerjanya sehingga hal ini mampu meningkatkan kebahagiaan dan kepuasan dalam diri. Hasil observasi dan wawancara diungkapkan mereka dapat mengatur work-life balance sehingga mampu menekan work-family conflict.

Selain itu peneliti mendapat informasi bahwa dengan bekerja dapat mengembangkan keterampilan sehingga mampu menyesuaikan diri dengan perkembangan jaman dan teknologi. Ibu yang berperan sebagai orang tua mampu memonitor anak melalui teknologi meski jarak dan waktu yang terbatas. Selain itu hubungan ibu sebagai wanita karir dengan anak tidak terpaut jauh karena kualitas pertemuan yang sangat baik dan terjaga melalui pendekatan-pendekatan yang inovatif (Djamauldin, 2018). Hasil penelitian sejalan dengan hasil temuan sebalumnya bahwa wanita yang bekerja dan sudah berkeluarga mampu menjalankann peran secara seimbang (Masita, 2019).

\section{KESIMPULAN}

Berdasarkan hasil analisis dan pembahasan mengenai seorang ibu yang memiliki peran ganda sebagai wanita karir menyebutkan bahwa bekerja merupakan ekspresi untuk mengaktualisasikan diri secara fisik dan psikologis untuk bersosilisasi dengan lingkungan, disamping mendapat reward berupa gaji sehingga dapat mandiri 
dalam berekonomi. Selain itu dengan bekerja wanita yang berpera ganda mampu mengatur work-life balance sehingga dapat tercapai kepuasan dan kesejahteraan dalam hidup. Disarankan untuk pnelitian selanjutnya dilakukan wawancara terhadap anak dan atau pasangan agar mendapatkan informasi yang lebih mendalam mengenai sistem dalam kehidupan sehari-hari melalui lingkungan sosial terdekat sehingga mampu memberi kualitas pertemuan yang lebih baik

\section{DAFTAR PUSTAKA}

Abalkhail, J. M. (2020). Women managing women: hierarchical relationships and career impact. Career Development International. 25 (4) 389 413. https://doi.org/10.1108/CDI-012019-0020

Ahmad, N. \& Tekke, M. (2015). Rediscovering Rogers's self theory and personality. Journal of Educational, Health and Community Psychology. 4 (3) 143 - 150.

Al-Asfour, A., Tlaiss, H.A., Khan, S.A. \& Rajasekar, J. (2017). Saudi women's work challenges and barriers to career advancement. Career Development International. 22 (2) $184-199$. https://doi.org/10.1108/CDI-112016-0200

Braun, S. \& Turner, R. A. (2014). Attitudes and company practices as predictors of managers' intentions to hire, develop, and promote women in science, engineering, and technology professions. Consulting Psychology Journal: Practice and Research. 66 (2) 93 http://dx.doi.org/10.1037/a0037079

Basrowi \& Suwandi. (2008). Memahami Penelitian Kualitatif. Jakarta. Rineka Cipta.
Clarke, M. (2011). Advancing women's careers through leadership development programs. Employee Relations. 33 (5) 498 - 515. https://doi.org/10.1108/01425451111 153871

Dewi, D. K. R., Suwendra, I W., dan Yulianthini, N. N. (2016) Pengaruh tingkat pendidikan dan motivasi kerja terhadap kinerja karyawan. e-Journal bisma universitas Pendidikan Ganesha. 4

Dhas, D. B. \& Karthikeyan, P. (2015). Worklife balance challenges and solutions: overview. International Journal of Research in Humanities and Social Studies. 2 (12) $10-19$.

Djamauldin, A. (2018). Wanita karir dan pembinaan generasi muda. Jurnal AlMaiyyah. 11 (1) 111 - 131.

Ermawati, S. (2016). Peran ganda wanita karier (konflik peran ganda wanita karier ditinjau dalam prespektif islam). Jurnal Edutama. 2 (2) 59-69.

Halida, O. (2013). Karir, uang, dan keluarga: dilemma wanita pekerja (studi fenomenologi wanita karir pada instansi kepolisian, keamanan, dan perbankan). Skripsi. Fakultas Ekonomika dan Bisnis Universitas Diponegoro. Semarang.

Hanurawan, F. (2012). Metode Penelitian Kualitatif Dalam Ilmu Psikologi. Surabaya. KPKM Universitas Airlangga.

Kaur, J. (2013). Work-life balance: its correlation with satisfaction with life and personality dimensions amongst college teachers. International journal of marketing, financial services \& management research. 2 (8) $24-35$.

Liu, T., Gao, J., Zhu, M. \& Qiu, Y. (2020). How career expectations influence advancement: evidence from women 
Dinamika Sosial Budaya, Vol 22, No. 2, Desember 2020, pp 165-170

p-ISSN: 1410-9859\& e-ISSN: 2580-8524

http://journals.usm.ac.id/index.php/jdsb

in the hospitality industry. Tourism

Review. https://doi.org/10.1108/TR12-2019-0513

Masita, T. S., Delyara, D. A., Fernando, M. L., Himmawan, G., \& Claudianty. G. S. (2019). Work-familly conflict dan work-life balance pada prajurit wanita TNI AL di Surabaya. Jurnal Fenomena. 28 (1) 39 - 44. DOI: 10.30996/fn.v28i1.2454

Mayangsari, M. D. \& Amalia, D. (2018). Keseimbangan kerja-kehidupan pada wanita karir. Jurnal Ecopsy. 5 (1) 43 $-$

50.

DOI:

http://dx.doi.org/10.20527/ecopsy.v5 i1.4884

Murtiana, T \& Hidayah, N. (2017). Kompleksitas peran wanita pada keluarga dengan pola karir ganda. Jurnal Pendidikan Sosiologi. 1 - 17.

Paramita, Paloma \& Waridin. (2004). Analisis pengaruh family friendly terhadap family balance dan program -work studi kasus pada rumah sakit panti wilasa citarum, semarang. Benefit: Jurnal Manajemen dan Bisnis.

Putri, J. G. (2019). Hubungan antara kebermaknaan kerja dengan kesejahteraan psikologis pada wanita yang bekerja di PT. AA Jakarta. Jurnal Psikologi Mandala. 3 (2). DOI:

http://dx.doi.org/10.36002/jpm.v3i2. 1095

Rogers, C. R. (1975). The emerging person: A new revolution. In R. I. Evans, Carl Rogers: The man and his ideas. New York. Dutton.

Shockley, K. M., DeNunzio, M. M., Shen, W. \& Arvan, M. L. (2017). Disentangling the relationship between gender and work-family conflict: an integration of theoretical perspectives using meta-analytic methods. Journal of
Applied Psychology. 102 (12) 1601 1635. http://dx.doi.org/10.1037/ap1000024 6

Sugiyono. (2011). Metode Penellitian Kuantitatif, Kualitatif dan $R \& D$. Bandung. Alfabeta.

Utami. (2011). Strategi work-life balance pada dosen perempuan berperan ganda (studi kasus di program studi arsitektur). Tesis, Universitas Gajah Mada Yogyakarta 